\title{
PERSONALITY TESTS IN JAPAN
}

\author{
HABUKU KODAMA
}

Japan Women's University

The history of Japanese psychology may be divided into the Pre- $W_{a r}$ and the PostWar periods by 1945, the year which brought the Pacific War (1941-1945) to an end. In the Pre-War period, it was largely under the Continental, particularly German influences, but the Post-War period marks the sudden onrush into Japan of American psychology. The study of personality in psychology is no exception.

As the personality tests that were tried or formulated in Japan before 1945, I can mention the Rorschach, a neurotice inventory, some versions of the extroversion-introversion tests and a few others.

In or about 1925, four years after its first publication in 1921, the Rorschach test was first introduced into Japan by Y. Uchida of Waseda University. A few years later in 1930, the first study or application of Rorschach to Japanese was reported by $T$. Okada in the Japanese Journal of Neurology and Psychiatry, followed by a few more studies by the same author in 1932 and 1935. Also in 1930 C. Fujisawa, then of Taiwan University, tested Takasago aborigines of Formsa with the Rorschach. In 1942 Motoaki of Waseda University published a study of $F$ responses of Japanese in Rorschach and in $1944 \mathrm{~S}$. Kuroda of Osaka University read a paper on the Rorschach at the regional psychiatric association meeting in Osaka. Of all personality tests, including inventories and projective techniques now in use or now being studied in Japan, the Rorschach occupies, in the opinion of the present writer, the dominant position and enjoys a widest use in the country.

I believe I can say there are five or six Rorschach centres now in Japan. The first is the Osaka University School of Medicine, the Neuro-Psychiatric Institute, which, headed by the late Dr. Horimi, has been most active in Rorschach studies in the last ten years or so. It has brought forth a number of normative and clinical studies in the field, including the clinical application of the Rorschach test to psychiatric and neurotic patients, the Rorschach responses of kindergarten and school children, and some experimental studies of the Rorschach tests. Their Rorschach tradition goes back to Dr. Kuroda above-mentioned, and their Neuro-Psychiatric Institute has been the most pro. ductive Rorschach research centre in the medical world in Japan. N. Kaneko is the present head of the Clinic, and G. Nagasaka, S. Tsuji, S. Takahashi and K. Hamanaka form the Rorschach group. They started the study of the Rorschach with clinical interest, and have since extended their studies to the genetic, normative and experimental aspect.

The honor of having first introduced the Rorschach to Japan belongs to Waseda University, Tokyo. Its psychological laboratory is another Rorschach research centre in Japan. Y. Togawa and H. Motoaki are two principal figures in the Waseda group of Rorschach workers, and their Department of Psychology may represent the largest gathering of clinically-minded psychologists in Japan. In 1950 they brought out the Waseda Rorschach. It is a series of ink-blots consisting of eight plates, four achromatic and four chromatic, and may be regarded as a sort of series parallel somewhat to the 
Rorschach, just like the Behn-Rorschach.

The Japan Women's University Institute of Child Study, with which the present writer is connected, is a third centre of Rorschach research in Japan. We were first of all concerned with the normative studies of Rorschach. Those who have been tested by us with the Rorschach number more than four thousand persons, from four years olds to the aged as old as eighty. It has been found that the norms given by foreign, especially American studies, are not always applicable to Japanese. New delineation of the location chart for certifying $D$ or $d$ areas in connection with $F$ or $F$-responses has been found necessary in view of the necessary changes to be made in interpretation of forms or colors depending upon differences in culture. Different norms according to age groups sometimes seem necessary. Different social or occupational groups, like doctors, preachers, priests, farmers, artists, musicians, prostitutes, etc. sometimes seem to require. somewhat remarkably different norms or interpretation. We are now undertaking the experimental validation study of personality and pathological signs in Rorschach.

Nagoya University Neuro-Psychiatric Institute is another Rorschach research centre. The Institute, headed by T. Muramatsu, could obtain the help of George DeVos, American clinical psychologist, who, having made a study of the cultural differences of the first and second generations of Japanese residents in the U.S. and American residents born and bred in America by the use of the Rorschach and TAT, came over to Nagoya University to pursue further studies of his theme. The Nagoya group of Rorschach workers set to cultural-anthropological studies of the people of Okayama, Western city, and a village in Mid-North Japan by means of the Rorschach. The Nagoya people are chiefly interested in the problem of interpretation of the test results, and have taken up the studies of several scales, like the scales of thought disturbances, affect disturbances, deviant verbalizations, etc. E. Murakami and A. Hoshino are young Rorschach enthusiasts of the Nagoya group.

The fifth is the Kobe Juvenile Classification Center group, consisting of M. Takahashi, H. Kawai, S. Yamamoto, and others, who have adapted Harrower's Multiple Choice Test for Japanese use, omitting those items which were not found in Japanese responses and substituting them with those items found more often among the Japanese.

The sixth group is represented by R. Satake, F. Tanaka and their associates of Kanazawa University Neuro-Psychiatric Institute, who are chiefly interested in the multiple choice or group Rorschach method after Harrower-Frickson as the fifth group.

Regarding the administration and scoring of the Rorschach, the Osaka group has its own system, but it is more inclined toward the Klopfer system, while the Nagaya group follows Beck more than the others. The Waseda group has developed its own plates of eight ink-blots, as was pointed out above, which are somewhat similar to but not the same as the originals. As for their interpretation, they follow Klopfer. The Japan Women's University Institute of Child Study has its own system, and it is entirely eclectic:

Thus it has been seen, as is naturally expected, that there are, in the method of administration, scoring, and interpretation, some, though not many, wide disagreements among those different systems. It was also the case with TAT, CAT and other projective techniques. A few years ago an attempt was made to get together the representatives and others of those research centres, so that they might organize themselves into a common research project, first, for the purpose of improving the uses of projective tech- 
niques in Japan; secondly for improving the confusing situation due to the different terminologies and methods of testing and scoring adopted by the different institutions, and thirdly, for bringing out, if possible, Japanese TAT better adapted to Japanese subjects. The project was realized, and being participated in by the Osaka, the Nagoya, the Waseda, the Kanazawa, the Japan Women's University groups and others, the co-operative studies went on a little while, but due to financial reasons, it came to an end to the regret of all those concerned.

The project was regrettably discontinued after only a year or so, but it came to develop into a different project of publishing the studies of the different research groups in one book or series of books, so that those interested in the Rorschach or TAT may take up the book and find a way out of the confusion of tongues with respect to the projective techniques. A book or series of volumes entitled "Psychological Diagnostic Methods" will be brought out in the near future. The same thing is expected to be done about TAT studies in Japan, which will form the third volume of the series.

Besides the Rorschach students referred above, there are found many stray Rorschach enthusiasts here and there. The stray group includes, among others, Y. Kataguchi of the National Mental Health Institute; K. Kiyozawa, of the Tokyo Metropolitan University; $\mathrm{S}$. Takahashi, of Kagawa University. The list is far from complete, as it will be seen from the fact that at the 21st Annual Congress of the Japanese Psychological Association to be held at Kyushu University on October 18, 19 and 20, twenty-two papers on the Rorschach test are going to be read. There are also a group of sociologists and ethnologists, such as K. Imanishi, Y. Maki, K. Fujioka, and M. Tomikawa of the Research Institute for Humanistic Sciences of Kyoto Univetsity, who have been doing some ethnological studies with the help of the Rorschach. S. Sofue, of the Tokyo Metropolitan University, is also an anthropologist and belongs to the Roarschach-oriented researchers.

The foreign writers on Rorschach who are most read by Japanese students of Rorschach include, in addition to Rorschach's Psychodiagnostik, the following:

Beck: Rorschach's Test. I, II, III. 1944-45

Bochner and Halpern: The Clinical Application of the Rorschach Test. 1945.

Halpern: A Clinical Approach to Children's Rorschach. 1953.

Bohm: Lehrbuch der Rorschachspsychodiagnostik. 1951.

DeVos: A quantitative approach to affective symbolism in Rorschach tesponses. 1952.

Harrower-Erickson: Large Scale Rorschach Techniques. 1945.

Klopfer and Kelly: The Rorschach Technique. 1942.

Klopfer et al: Developments in the Rorschach Technique. I, II. 1954, 1956.

Piotorwski: The Rorschach Compendium. 1950.

Rapaport et al: Diagnostic Psychological Testing. 1945.

Schafer: The Clinical Application of the Rorschach Testing. 1954.

Ames et al: Child Rorschach Responses. 1952.

Ames et al: Rorschach Responses in Old Age. 1954.

Herz: Frequency Tables to be used in Scoring the Rorschach Ink-blot. 1942.

Buhler et al: Rorschach Standardization Studies. 1949.

Munroe: Prediction of Adjustment and Academic Performance of College Students by a Modification of the Rorschach Method. 1945.

Schachtel: Articles in Psychiatry.

Phillip and Smith: Rorschach Interpretation; Advanced Technique 1953.

Now to turn to TAT's, there are available in this country at present three different sets of it. The first is the Waseda set of 16 pictures and one blank plate published in 
1953. It is an output of the co-operative work of $Y$. Togawa and $H$. Motoaki, both of Waseda, and F. Shinagawa of the Tokyo Liberal Arts College and others. The second is the series turned out by the Neuro-Psychiatric Institute of Nagoya University, for which Y. Marui was chiefly responsible. The third set to come out was the TAT of the Psychiatric Institute attached to the Musashino Psychiatric Hospital, of which $K$. Sano and $\mathrm{H}$. Makita are the co-authors. I am not going into detail in discussing the Japanese TAT's, but one word will not be out of place here. When you compare Japanese pictures, of whatever version, with Murray's, there is one thing that impresses one. It is: that Japanese pictures are, generally speaking, more beautiful, - I am not speaking in the artistic sence-, more "soft", less powerful, less horrible, less fear-provoking, less "stirring" than Murray's version, so that some psychologists here are sceptical about the possibility of the Japanese pictures drawing out what lies at the innermost depth of the . hardened human heart. Thus there are many Japanese psychologists who are using Murray instead of Japanese versions of TAT. The Japanese artist, who was asked to draw pictures for the Nagoya TAT is reported, when he was shown Murray pictures, to have been remarkably impressed with the latter and observed that no Japanese artist might be able to draw pictures of Murray's power. Contrary to the opinion expressed above, however, the softened tone of the Japanese pictures might, it is argued, appeal better to Japanese sentiment, and serve the purpose of the test better.

Corresponding to Bellack's CAT or Blum's Blacky Pictures, we have here the Waseda CAT; S. Yamamoto, O. Nishimoto, and I. Yoshii's RCAT, which is the abbreviation for the Rabbit Caricature Apperception Test for kindergarten and lower grade children; and Sugihara and Okino's Revision of Blacky Pictures of the Osaka University Medical School. The Waseda CAT published last spring is, as is the Waseda TAT, a co-operative product of $Y$. Togawa and $\mathrm{H}$. Motoaki, both of Waseda, and K. Matsumura, of Ochanomizu University and others. The Japanese TAT's, all three versions of it referred to above, have much similarity in themes and pictures to the American version, but with the Japanese CAT's, you will find wider differences from the American prototypes than do the Japanese TAT's. The animals of Japanese versions, as in the case of TAT's, look more "soft", more cheerful, more bouyant, but less powerful, less rough, less commanding, less of a rogue than the American animals. Also some Japanese pictures depict a scence where a great many animals make their appearance, which is not the case with the American version. I do not know which of the two will serve the clinical purpose better, but it must be admitted that the difference is what the racial or cultural differences made.

Other varieties of Japan-adapted or Japan-made projective testing instruments include Szondi, Wartegg, SCT, Rozenzweig, Uhrbrock and Downey, and CST. The last-named stands for color symbolism test and is a Japanese device by T. Obonai and T. Matsuoka. For more detailed information, the reader is referred to the article entitled "The color symbolism personality test" in the Journal of General Psychology, 1956, 55, 229-239. But to put it in a nutshell, the test consists of the stimulus words and color table. The examinee is asked to look at all the colors on the test sheet during the test. The examiner reads the stimulus words one by one, and at the same time shows the stimulus words written on a card individually to the examinee. The examinee chooses the color suitable for expressing the affective impression evoked at the moment he hears and sees the given stimulus word. The color table is composed of white, pink, black, gray, blue, 
yellow brown, red violet, purple, red, light blue green, blue violet, dark vinaceous purple, and green. The stimuli include $\mathbf{4 0}$ words such as, for instance, fear (terror), uneasiness, irritation, love, anger, fatigue, and home. The principle of the test is that every color contains not only its own sensation attributes but also some affective symbolic properties that reflect the observer's own life experience or personality. The authors conclude that the test may diagnose personality fairly well, especially schizophrenic, neurotic and delinquent types.

As to Rosenzweig Picture-Frustration Study, K. Sumida and K. Hayashi of Kyoto Liberal Arts College adapted it for Japanese use by the cooperation of the original author, and are intending to use it for cross-cultural comparison as well as for personal diagnosis. There are several Japanese versions of SCT in use now, but the forms being used most of all may be the three forms of the SCT published by K. Sano and H. Makita, of the Psychiatric Institute, Tokyo. About Szondi, R. Satake, of Kanazawa University has almost made his speciality of it and has recently brought out a study on it.

Kent-Rosanoff's word association test was adapted for Japanese use by $Y$. Kubo in 1926. In 1930 O. Fujisawa, then director of Kyoto Prefectural Youth Clinic, which was one of the pioneering institutions of the kind in Japan, published an introversionextraversion test, and a study of word asssociation of one thousand primay school children with the collaboration of S. Maekawa. The test has since apparently been left neglected for a long time, but recently there are indications that interest in it for diagnostic purpose has been revived.

A projective approach to personality study through the sound stimulus was recently started by Y. Mizuguchi and others of Kagawa University in 1955, and by T. Matsui and $K$. Umezu, of the Institute of Psychiatry, Tokyo, in 1957.

Before proceeding to the inventories, I wish to take up the performance type of projective tests, including Uchida-Kraepelin's Psycho-diagnostic Test, Kirihara-UhrbrockDowney's Will-Temperament Scale, and the HFDT. Y. Uchida's test is dealt with more extensively in this journal elsewhere, but I just want to point out that Uchida maintains the Psycho-technological Institute, and has a large following in the industrial circle and among the penitentiary people. The test is simple to administer and easy to score, and much research has been done in connection with its practical use for diagnosing abnormal cases as well as predicting industrial efficiency. The test has become so popular that some shrewed testees, studying beforehand the patterns of work curves, have come to consciously imitate the normal or optimal patterns of work curves. Y. Kirihara, the former head of the Institute of Labor Science, adapted Uhrbrock-Downey's Will-Temperament Scale for use with Japanese in 1929. H. Ogita, of the Osaka Prefectural Institute of Educatonal Research, published a study on the Human Figure Drawing Test for detection of juvenile delinquency.

About personality inventories, there are a great many of them now in use here. Some of them have been made after Anerican patterns; others are adaptations for Japanese use of American tests, while there are a few original Japanese tests. It is often difficult in these days to distinguish things Japanese from importations or imitations of foreign devices in the sphere of psychological test, as in some other areas of cultural products. Let me enumerate, first, those inventories that were formulated before the Pacific War. 
In 1924 S. Nakajima published a mental test of morals. S. Otomo, now of the Kwansei Gakuin University, on return home from his doctorial work at the University of Chicago, started publishing in 1926 as the director of Nomura Institute for Educational Research, Osaka, test after test of intelligence, achievement and personality. His tests were extensively used by teachers, and he wrote a book consisting of two large volumes entitled "Educational Diagnostics", in which he describes most of his tests. The emotional stability test was his first personality test brought out in 1926. In the same year Y. Kubo published, as was mentioned above, his adaptation for Japanese of Kent-Rosanoff's word association test. These three tests were the forerunners in Japan of personality inventories, in whatever form.

In $1927 \mathrm{~T}$. Watanabe and his associates, of Nihon University, brought forth a personality adjustment questionnaire. $Y$. Kubo, who was a very prolific worker, turned out in 1929 a scale for the assessment of personality. In $1930 \mathrm{~S}$. Ishikawa, now of Yamanashi Universty, published an interest test based upon Spranger's value system. In the following year Y. Awaji and Y. Okabe brought out Emotionailty Inventory, which was somewhat patterned after Mathews-Woodworth Inventory and others.

The period from 1931 to 1944 prior to the outbreak of the Pacific War saw the publication of the following tests, among others, relating to personality.

1931 S. Otomo: Ethical Judgement Test

S. Otomo: Interest Tests (4 forms)

S. Otomo: Personality Assessment Scale

1933 Y. Awaji : Extroversion-Introversion Test

Y. Awaji : Scale for Personality Assessment of Young Children

Utsunomiya and Mizuno: Extroversion-Introversion Test

K. Matsumiya : Scale for Attitude toward the Church

Y. Koga: Scale for Attitude toward Sports

1936 Y. Uchida : Uchida-Kraepelin Psychodiagnostic Test

1938 T. Watanabe: Masculinty-Femininity Test

1944 Y. Ushijima : Environment and Personality Assessment Scale Y. Ushijima : Personality Test

The above is not an exhaustive list, but it covers, I believe, most of the personality inventories in the widest sense of the term that were brought out in the two decades prior to the War. There were so few of them existent in those days. The Japanese came to take a liking for the Uchida-Kraepelin test, and the extroversion-introversion test, of which there are, besides the ones mentioned above, several more different versions. With Ushijima's tests, the Pre-War period came to an end in 1945.

The Post-War period that followed is characterized, as has been pointed out above, by the rapid and steady influx into Japan of American psychology. The first practical imprint after the War of American assessment technique on Japanese psychology is found in the descriptive scales for personality and behavior assessment of primary and secondary school children, which were prepared by the committees on tests appointed by the Ministry of Education. It was during the period of American Army occupation of Japan, and every such project was started, under the suggestion, and supervised by, the Civil Information and Education officers of the U. S. Occupation Forces. Samples of descriptive items were given by the American advisers, including one or two psychologists, and the committes, on one of which the present writer happened to serve, worked on the 
suggested samples and prepared the scales in 1948-49. The descriptive scales thus prepared were circulated to all the primary and secondary schools for use of their teachers. These descriptive scales, which might perhaps have passed unnoticed outside of schools, proved, at least for a few years, an important, the only, tool in the hands of school teachers all through the country for evaluation of their pupils. They might be rather crude enough tools, I believe, but for want of any other instrument, they served to orient the teachers to new education and its assessment technique instead of the old-fashioned check lists.

For historical interest, the items of each scale are given below, as the part they played in the education of the day was, in my opinion, very significant.

Primary school

1. Friendly

2. Respect others

3. Accept other's standpoint

4. Co-operates with others

5. Zeal in work

6. Responsible

7. Perseverance

8. Planning and resourceful

9. Self-controlled

10. Independent in judgement

11. Righteous

12. Critical power

13. Feeling of security

14. Leadership

15. Cheerful in attitude

16. Courteous in manners

17. Understand and observe rules

18. Curiosity

19. Aesthetic attitude

20. Careful about health

21. Enjoy labour

22. Take good care of things

23. (Any other item regarded as important to be added in here)
Secondary school
1. Sociability
9. Atritude of respect
13. Tolerant attitude
10. Co-operative attitude
12. Responsible attitude
17. Creativeness (?)
14. Independent character
4. Fair judgement
5. Feeling of security
11. Leadership
2. Happiness or cheerfulness
8. Kindness and courtesy

3. Succesfulness
4. Emotional stability
7. Self-confidence
15. Honesty
16. Worthy use of leisure

The Japanese version of Germane and Germane's Vocational Interest Inventory was a by-product of the same committee and was published by the Japan Vocational Guidance Association in 1949. The committee, which was originally entrusted with the task of investigating the situation of Japanese mental tests, made an inventory of mental tests in Japan with evaluations attached.

In $1949 \mathrm{Y}$. Ushijima brought out a Japanese version of social maturity scale after Doll. The other personality tests that followed, too, bear the mark of new trends of psychology, that is, dynamic, motivational, psychoanalytical, or home-, school-, and socialenvironment-diagnostic in adddition to neurotic or psychopathic characterization.

1949 S. Nagashima and M. Yamazaki : Adjustment-Diagnostic Test. (for 5th to 8th graders)

1950 S. Yamamoto: Fundamental Needs Test.

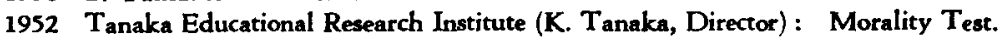


Tanaka Educ. Res. Inst. : Environment-Diagnostic Test.

Tanaka Educ. Res. Irst.: Home-Diagnostic Test.

Tanaka Educ. Res. Inst : Behavior Disorder Diagnostic Test.

1954 T. Kondo and T. Kobayashi: Bernreuter Personality Inventory.

1954 N. Nanjo: N-N M-F (Masculinity-Feminimity) Test.

H. Sakata : Test of Moral Judgment.

1956 M. Masaki : Personality Inventory for Guidance.

Y. Ushijima : Personality Inventory. (for 5th to 9th graders)

H. Hashimoto et al : Guess-Who Test.

H. Tazaki, M. Hasegawa et el: Adjustment-Diagnostic Inventory.

T. Yatabe et al: Yatabe-Guilford Personality Inventory

K. Saro and H. Makita: Personality Inventory.

M. Ohmura : Emotionality Inventory

1957 S. Nagashima and K. Fujiwara: Personality Inventory.

The adjective "diagnostic" attached to many of the tests mentioned above may not. mean much, as any test may be regarded as diagnostic in analyzing aspects of personality or environment, but it will imply the uses to which those tests are first intended to be put, and the interest attached to it. Dynamic, motivational study of personality and the clinical interest underlying it characterize the personality tests recently made or now being made here. It goes without saying that the trend is world-wide.

An original, unique test called "Tension-for-equilibration" test was devised by $M$. Abbe in 1950. The group method, which is more characteristic of this test than the individual method, consists in asking each testee to assess a given friend of his in its group by checking 25 pairs of opposite trait names, then another friend assigned to him. After the second checking is done, he is shown the trait names which have been filled in for the testee by a certian friend of his unrevealed to him in the group. The occasion is intended to create a critical moment for the testee and thereby to provoke him to expose himself more unguardedly to observation. For the third time he is asked to check a list of the same trait names for a third friend of his in the group. Abbe holds that the checks the testee has made for each of his friends represents, especially when the same trait name is checked for different friends, an aspect, a subjective aspect of the personality of the testee. The trait names that are filled in for the testee himself by his friends represents the objective aspect of his personality. The testee's reaction that might be shown in the change of the response tendency represents a reflecive aspect of his personality. Also V. Q., that is, the extroversion-introversion quotient is calculated depending upon the trait names checked, as well as $A$. Q., that is, ambivalence quotient which is obtained by the following formula.

$$
A . Q=\frac{\text { No. of opposite trait names repeatedly checked }}{\text { No. of trait names repeatedly checked }} \times 100
$$

Whenever one finds in others a defect or an excellent point, he tries to displace the unbalance between his behavior and other's or restore the balance lost, which creates a rensional state. The test is intended to approach personality through the measurement of the tension for equilibration, by means of the check list which has been determined experimentally beforehand. The test was revised in 1952 as an individual test.

In $1951 \mathrm{~K}$. Matsumura, T. Oguchi and A. Onda devised S-E-T (self-extention test) of high originality to grasp the modes of the self for personal assessment as well as for the counselor's diagnosis. 1956 saw the output of several personality inventories. Of these tests recently constructed, the Yatabe-Guilford Personality Inventory, and $M$. 
Ohmura's Emotionality Scale, which is based upon Taylor's Manifest Anxiety Scale, will be dealt with more in detail respectively in a different paper in this journal. Kimura and Nobechi's "Study of Values" of Japanese in comparison with Allport's will also be reported in another paper here. An increasing number of Japanese psychologists are getting clinically-minded, and a correspondingly increasing number of studies in the personality and clinical fields are being done. The short scale of Taylor's seems to have attracted attention of many Japanese psychologists. There are more than ten papers on the subject read in the psychology conventions, including the studies from the psychological laboratories of Ibaragi University and of Nihon University. As to the MasculinityFemininity Test, Watanabe and Muranaka published a simplified Japanese adaptation in 1950, and Y. Nogami is now revising it. Nogami has been conducting a comprehensive study on the masculinity-femininity problem since 1953, based on behavioral and physical traits as well as character traits obtainable through self-diagnosis. M. Nanjo has devised N-N and N-N-N Masculinity-Femininty Test and used it for his study of the personality structure of inhabitants in some detached islands.

Last but not the least, the Minnesota Multiphasic Personality Inventory should find a place in this inventory of personality tests in Japan. To tell the truth, the present writer was the first Japanese to take it up for study here. He was much attracted by the really multi-dimensional nature of the inventory and the idea of the lie scale and other validation techniques of the test. In 1950 he translated the whole 550 items of the test into Japanese, and having slightly modified the items or rather the wording to suit Japanese testees, administered the test to more than 2,000 normal Japanese. He then proceeded to undertake the construction of Japanese scale for schizophrenia, hyochondriasis, hysteria, psychasthenia, and others. He was then joined in the study by Y. Shioiri, a psychiatrist formerly of the Medical School of Keio University. However, they found the job a very difficult one. In the first place, it took a normal Japanese nearly one hour at the quickest, and often even much longer, to go through the whole test in one session. The testees felt not a small number of items strange to their sentiment, and sometimes even difficult to understand. They also responded to some items not in the way average Americans are expected to, but rather in the opposite way. We literally tackled with the work, and having taken out or added items, and revising many original items to suit Japanese cases, finally obtained a shortened form of 359 items. This much improved the situation, and we could obtain tentative scales for schizophrenia, depression, hysteria, epilepsy, general paralysis, drug addiction, psychopathic personality, neurasthenia, etc. We do not believe that the shortened form is the best we could manage to bring out, and are still engaged in further studies so that the Japanese version may serve as a more reliable diagnostic instrument. J. Inami and others of Kyushu University Medical School are using the MMPI with patients of the tuberculosis ward. N. Hidano, of the School of Education, Tokyo University is trying the whole scale (group form) on students in connection with counseling work. The Psychiatric Institute of Tohoku University, Sendai has also started study on the Minnesota Inventory. Thus the indications are that the MMPI, which has rather long been unnoticed or neglected, but has begun to loom large lately among clinical psychologists and psychiatrisis in Japan. The MMPI is also supplying materials, as in the case of Taylor's Anxiety Scale, for construction of other tests.

The present writer is also engaged in the construction of the Japanese version of the Strong Vocational Interest Inventory, which is used for clinical purposes as well as for 
vocational guidance. He has been working on it since 1950 , but it was not an easy going. The most important reason is that Japanese adults are reluctant to take a test, and it was really difficult to get the consent of business men, financiers, scientists, professors, school teachers, engineers, etc. to get tested with the draft inventory. Recently, however, I have finally succeeded in the hardest part of the job, that is, securing responses for the draft inventory of more than 200 leading businessmen, and nearly 200 leading engineers of the country. Other occupations have also been covered. It will now be only a matter of months that the Japanese verion of the Strong test, in a slightly shortened and modified form, will be turned out. Besides Germane and Germane's Vocational Interest Inventory above mentioned, we have now in Japan the following vocational interest inventories.

Masuda and Takahahashi : Vocational Interest Inventory

F. Fujiwara : Vocational Interest Inventory (patterned after Kuder)

Tanaka Educ. Res. Inst. : Vocational Interest Inventory

The survey is not complete, nor is it very systematic. In concluding the survey, however, I wish to characterize the present situation of personality inventories in Japan somewhat in the following words. The Japanese psychologists, finding themselves equipped with few diagnostic testing instruments, are now busily engaged in constructing or locating tests suitable to their purposes. Secondly, with a few exceptions, many of the tests are adaptations or imitations of foreign devices, a situation that may be unavoidable in any country to a certain extent. Thirdly, those tests that have been brought out, generally speaking, do not have a wide circulation. Many of them are being used only within the confine of the laboratory where it was made.

A few studies and publications that have not been touched upon in the article proper are also included in the bibliography that follows.

\section{BIBLIOGRAPHY}

1. Abbe, M. A method of personality assessment. Kyoto: Minerva-shobo, 1953.

2. Awaji, Y. A manual for the version test (Extroversion-Introversion) Tokyo: Yamakoshi, 1933.

3. Awaji, Y. A method for fersonality assessement of school children. Tokyo: Yamakoshi, 1934.

4. Awaji, Y. A version test manual (Revised) Tokyo: Koyomondai-Kenkyukai, 1949.

5. Awaji, Y., \& Okabe, Y. Emotionality inventcry. Tokyo: Aiiku-kai, 1931.

6. Fujisawa, O. Evaluation of introversion-extraversion. Proc. of Kyoto Pref. Youth Clinic, No. 3, 1930.

7. Fujisawa, O., \& Maekawa, S. A study of word association of 1,000 primary school children. Proc. Proc. of Kyoto Pref. Clinic, No. 3, 1930.

8. Fujisawa, C. Psychological study of the Takasago Tribe in Formsa. Minzokugaku-kenkyu (J. Ethnology) $1953,18$.

9. Fujiwara, K. Vocational interest inventory (for high school students). Tokyo: Kaneko-shobo, 1951.

10. Hashimoto, J. et al. Self-diagnostic test (for elementary school children). Tokyo: Nihon-Toshobunkakyokai, 1956.

11. Hashimoto, J. et al. Guess-who test (forms for elementary school, middle school and high school children). Tokyo: Nihon-Toshobunkakyokai, 1956.

12. Huzioka, Y. A personality survey based on the Rorschach test (1). Social survey report of the Research Insitute of the Humanistic Sciences, No. 8, Kyoto University 1952.

13. Imanishi, K., Maki, Y., Tomioka, M., \& Huzioka, Y. A personality survey based on the Rorschach test. (2) Social suvey report of the Research Institute of the Humanistic Sciences, No. 9, Kyoto University 1953.

14. Imanishi, K., Maki, Y., \& Huzioka, Y. A personality survey based on the Rorschach test. Studies of the Tachikui Kiln Area, 1955.

15. Ishikawa, S. A manual for Interest-Type Test. Tokyo: Fujishoten, 1930.

16. Ito, S., Komiyama, E., Hasegawa, M., \& Tazaki, H. Behavior problem diagnostic test (for 7th to $12 \mathrm{th}$ graders). Tokyo: Nipponbunkakagakusha, 1930.

17. Joya, T. On the results of the Rorschach test administered to the mentally-retarded. Hokuetsu Medical Ass. J, 1942, 57, 1151. 
18. Kataguchi, Y. Psychological diagnostic method: Rorschach. Tokyo: Maki-shoten, 1956.

19. Kataguchi, Y. The development of the Rorschach test in Japan. J. proj. Tech., 1957, 21.

20. Kirihara, Y. Revised Will-Temperament test and its norms. Tokyo: Yamakoshi, 1930.

21. Kodama, H. A normative study of Japanese responses in Rorschach Test. Series in Psychology, Vol. 7, Tokyo: Nakayama-shoten, 1953.

22. Kondo, T., \& Kobayashi, T. K-K revised Bernreuter personality inventory. A manual. Hiroshima: Busshindo, 1956.

23. Kuroda, S. A study of Rorschach test. A paper read at the 30th Kinki Psychiat. Meeting, 1944.

24. Kuroda, S. A study on epilepsy. A paper read at the 30th Kinki Psyschiat. Meeting, 1944.

25. Marui, F. Diagnosis of family relations by TAT. Nagoya Univ. Fac. of Educ. Monogr., 3. 1956.

26. Masaki, M. Personality inventory for student guidance (I.C. G.-- L. S.S. forms for 7th to 9 th graders). Tokyo: Kaneko-Shobo, 1956.

27. Matsui, T., \& Umezu, K. Study on the projective use of the sound stimulus. 1957. Inst. of Psychiat. Bull. No. 3.

28. Matsumura, K., Oguchi, T., \& Onda, A. The S.E-T (Self-Extention Test). Tokyo: Bunkyo-shoin, 1952.

29. Minakuchi, Y. et al. A study of personality through the medium of sound. Abstracts of papers read at the 18th Annual Meeting of JPA. 1955.

30. Miyada, Y. et al. Rorschach responses of feeble-minded children. Jap. J. Psychol. 1943, $17,69$.

31. Motoaki, H. A study of F responses in Rorschach. Jap. J. Psychol., 1942, 17.

32. Motoaki, H. A manual for clinical psychodiagnosticr. Tokyo: Kanekoshobo, 1942.

33. Murakami, E., \& Emi, Y. A study of the Rorschach ranking test. Jap. J. Psychol., 1956. 27, 185.192.

34. Nagasaka, G. Studies on the Rorschach test. Psychiat. et Neurol. Jap., 1952, 4, 219-253.

35. Nagasaka, G., Tsuii, S., Takahashi, K, Hamanaka, K., \& Asai, K. Rorschach responses of elementary school children in Osaka, 1952. (A mimeogrpahed copy).

36. Nagashima, S., \& Yamazaki, M. Adjustment daiagnostic test (for 5th to 8th graders). Tokyo: Kanekoshobo, 1949.

37. Nagashima, S., \& Fujiwara, K. Personality diagnostic test manual. Tokyo: Kanekoshobo, 1957.

38. Nakamura, K. Mooney check list, Japanese version. Tokyo Univ. Student Counseling Center, 1956.

39. Nanjo, M. N-N Masculinity-Femininity test. Construction and standardization. Nagasaki Pref. Women's Junior Coll. Bull. No. 21954.

40. Nanjo, M. N-N-N (New-Nagasaki Nanjo) Masculinity-Femininity test. Proc. 21 st Convention of JPA, 1957.

41. Nogami, Y. Studies on the masculinity-femininity problems. I-V, 1955-1957. Proc. 21. Conventions of JPA, etc.

42. Obonai, T., \& Matsuoka, T. Color symbolism personality test (Revised). Tokyo: Nakayamashoten, 1956.

43. Ogino, H. Studies on the Bender Gestalt test. Osaka Unir Med. J., 1955, 7, 735-742.

44. Okada, T. An experimental study of Rorschach's psychodiagnostics. Jap. J. Psychiat. \& Neurol., 1930, 32, 361-375; 433-441.

45. Okada, T. A qualitative classification of responses in Rorschach psychodiagnostics and an analysis by this method of an abnormal statement. Jap. J. Psychiat. \& Neurol., 1932, 35, 147-190; 249-266; 336-368.

46. Oogita, H. A study of HFDT for detection of juvenile delinquency. Educ. Res. Inst. Osaka Pref. 1955.

47. Sakata, H. Moral judgment of high school students. Report of the survey of the Fushimi High School. 1955.

48. Sano, K., Makita, H., \& Umezu, K. A normative study of Seiken-shiki TAT pictures. Bull. Inst. Psychiat., No. 2, 1955; No. 3, 1556, Tokyo.

49. Sano, K., \& Makita, H. The construction of the Seiken-shiki TAT pictures. Tokyo: Inst. Psychiat., 1956.

50. Sano, K. Makita, H., \& Sakabe, S. Sciken-shiki fersonality inventory. Tokyo: Inst. Psychiat., 1956.

51. Sano, K., \& Makita, H. Seiken-shiki Sentence Completion Test (MF forms). Inst. Psychiat., 1956.

52. Satake, R. A study of Rorschach ink-blots. J. Juzen Med. Ass., 1956, 51.

53. Satake, R. Rorschach test. Series in Abnormal Psychology. Tokyo: Misuzushobo, 1954.

54. Satake, R. An introduction to Szondi Test. Classification Materials No. 1, Correction Bureau of the Ministry of Justice, 1957.

55. Sakakibara, K. A manual for version test ( 3 forms). Tokyo: Kanekoshobo, 1950.

56. Sofue, L Patterns of Japanese personality. Proj. Tech. (Japanese), 1954, 1. 
57. Sumida K., \& Hayashi, K. Rosenzweig P-F study, Japanese version (fot children over 15 years old and adulcs), Kyoto: Sankyo-bo, 1957.

58. Suzuki, K. Shinagawa, F. Mamiya, T., \& Tatsumi, T. Mental health diagnostic test manual. Tokyo: Nipponbunkakagakusha, 1955.

59. Suzuki, K., Mamia, T., Shinagawa, F., \& Tatsumi, T. Morality diagnostic test. Tokyo: Nipponbunkakagakusha, 1952.

60. Suzuki, K. Mamiya, T., Shinagawa F., \& $\mathrm{T}_{\text {atsumi, }}$ T. Home environment diagnostic test. Tokyo: Nipponbunkakagakusha, 1953.

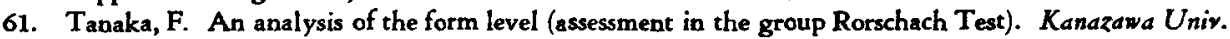
Faculty of Law and Letters Psychol. Monogr., 1956.

62. Tanaka, F. On the number of responses in Rorschach Test. Kanazasa Univ. Facalty of Las and Letters Monogr. 8, 1956.

63. Tanaka, K., \& Yamamoto, M. New version test (Extroversion-Introversion): Elementary and middle school form. Tokyo: Kanekoshobo, 1950.

64. Tanaka, K. Tanaka version test manual. Tokyo: Kanekoshobo, 1949. The manual contains a comparative study by the author of the extroversion-introversion scores of various nationalities in the Ear East and the American-born Japanese and other American-born nationalities in the United States.

65. Togawa, Y. Thematic apperception test manual. Tokyo: Kanekoshobo, 1953.

66. Togawa, Y, Motoaki, H., \& Matsumura, K. et al. Children's Apperception Test manual. Tokyo: Kanekoshobo, 1957.

67. Tsuji, S. Studies on the Rorscach Test, 1956 (a mimeographed copy).

68. Tsuji, S., Hamanaka, K, et al. Rorschach responses of kindergarten children, 1956 (a mimeographed copy).

69. Uchida, Y. Uchida-Kraepelin psychodiagnostic test: A practical manual (Revised). Tokyo: Japan Psycho-technological Institute, 1951.

70. Uchida, Y., \& Koboyashi, M. Uchida-Kraepelin psychodiagnostic test for child guidance. A manual. Tokyo: Japan Psycho-technological Institute, 1954.

71. Ushijima, Y. Environment and personality diagnostic test manual. Kanekoshobo, 1944.

72. Ushijima, Y. Manual for personality test (for 5th to 9th graders). Tokyo: Kaneko-shobo, 1944.

73. Wada, T. Studies on TAT. Psychiat. et Neurol. Jap., 1952, 6, 254-267.

74. Watanabe, T., \& Muranaka, K. A manual for simplified masculinity-femininity test (for upwards of 5th graders). Tokyo: Kaneko-shobo, 1951.

75. Yamamoto, S., Nishimoto, O., \& Yoshii, T. RCAT for kindergarten and elmentary school children. Kobe: Kyoikubunka-sha, 1955.

76. Yokota, S. Uchida-Kraepelin psychodiagnostic test. A manual. Tokyo: Kaneko-shobo, 1949.

77. Yoshida, S. Studies on Szondi Test.Osaka Univ. Med. J., 1955, 8, 713-726.

MS. received $\times 7,57$.

Habuku Kodama (炕 Ti省, 1896- ), Ph. D. (Univ. of Chicago) 1918-21, Newsman, Osaka Mainichi Shinbun; 1929-38, Professor of Keio University; 1938- Professor of Japan Women's University, Director, Institute for Child Study, Toshima-ku, Tokyo. Fourth President of Japan Association of Applied Psychology. Publication-Books : A Japanese adaptation of WISC, 1953. Adolescent psychology, 1952. Etc. Articles : 1953, Methods of personality assessment. 1957, Japanese standardization of WAIS. etc.

Writers (p. 104-109) : Seiichi Kuraishi (合石精一, 1909- ), graduated from Univ. of Tokyo in 1932. 1944-45, Chief, Aptitude Test. Dept. for Army Aviation Personnel ; 1949- Professor, Gumma University; 1954- Professor of Psychology, Kyoto University. Publication : 1938, On the recall of simple thought forms by prompting method. 1957, Factorial structure of sociality developmental test. Etc.

Masahide Kato (加藤正英, 1903- ), graduated from Kyoto Univ. in 1928-1938, Consultant, Kobe Institute for Child Welfare; Counsellor, Osaka Bureau for Vocational Guidance; 1951-56, Professor, Osaka Prefectural Univ.; 1954 Professor of Prychology, Nara Women's Univ. Publication-Book: Child psychology for nurses. 1935. Survey of vocational guidance system. 1952. Articles : 1935, An experimental genetic study of behavior forms in "the ball and field test" Developmental tests of young children. 1935. Etc. 